\title{
Determinación fenotípica de subpoblaciones de células madre derivadas de sangre de cordón umbilical
}

\author{
Viviana Marcela Rodríguez ${ }^{1}$, Adriana Cuéllar ${ }^{1}$, Lyda Marcela Cuspoca ${ }^{1}$, \\ Carmen Lucía Contreras ${ }^{1}$, Marcela Mercado ${ }^{1}$, Alberto Gómez ${ }^{2}$ \\ ${ }^{1}$ Grupo de Inmunobiología y Biología Celular, Laboratorio de Hematología, Departamento de Microbiología, \\ Facultad de Ciencias, Pontificia Universidad Javeriana, Bogotá, D.C., Colombia. \\ 2 Instituto de Genética Humana, Facultad de Medicina, Pontificia Universidad Javeriana, Bogotá, D.C., \\ Colombia.
}

Introducción. La sangre de cordón umbilical humana es una alternativa para la obtención de células madre hematopoyéticas; sin embargo, no es clara la expresión conjunta de los antígenos CD34, CD38 y HLA-DR, ni de antígenos embrionarios asociados con este tipo de muestra.

Objetivos. Determinar la expresión en membrana de los antígenos CD34, CD38 y HLA-DR, así como de los antígenos embrionarios SSEA-4 (Specific Stage Embryonic Antigen-4) y CD13. Materiales y métodos. El estudio se realizó en muestras de sangre de cordón umbilical obtenidas de ochenta mujeres en estado de gravidez normal a término que asistieron al servicio de ginecobstetricia del Hospital Universitario San Ignacio. Los antígenos se determinaron mediante citometría de flujo.

Resultados. El rango de células CD34+ presentes en sangre de cordón umbilical humana fue mayor al 0,2\% ( $p=0,0010)$ : a partir de esta población el rango de CD34+/ CD38-/ HLA-DR- fue de $0,0153 \%$ a $0,0234 \%$, de CD34+/CD38+/HLA-DR- fue de 0,0191\% a 0,296\%, de CD34+/ CD38-/HLA-DR+ fue de 0,0427\% a 0,0676\%, y de CD34+/CD38+/HLA-DR+ fue de 0,2427\% a 0,5117\%. La expresión de los antígenos embrionarios SSEA-4 y CD13 se determinó con el mismo método y se encontraron ocho muestras positivas para la expresión de estos antígenos. Conclusiones. El fenotipo que se expresa con mayor frecuencia en sangre de cordón umbilical corresponde a CD34+ CD38+ HLA DR+; además, el hallazgo de antígenos embrionarios podría indicar que en sangre de cordón umbilical humana existen poblaciones celulares con fenotipos similares a los progenitores celulares adultos multipotentes (Multipotent Adult Progenitor Cells) descritos en médula ósea.

Palabras clave: células madre hematopoyéticas, citometría de flujo, cordón umbilical, trasplante de células madre.

Phenotypical determinants of stem cell subpopulations derived from human umbilical cord blood

Introduction. Human umbilical cord blood (HUCB) is a common source of hematopoietic progenitor cells; however, coexpression of CD34, CD38 and HLA DR antigens and of embryonic antigens (SSEA-4 and CD13) have not been described in HUCB.

Objective. The current study attempted to identify in HUCB the presence of these antigens.

Materials and methods. Cord blood samples were obtained from 80 women with normal pregnancies, who were attending the gynecology-obstetrics service of the San Ignacio Hospital, Bogotá (Colombia). The antigens were identified with a FACS Calibur BDO flow cytometer and a cocktail of monoclonal antibodies.

Results. The population of CD34+ cells in HUCB was higher than $0.2 \%(p=0.001)$. The levels of additional cell subpopulations were as follows: CD34+/CD38-/HLA-DR-0.015\%-0.023\%, CD34+/CD38+/HLA-DR-0.019\%-0.30\%, CD34+/CD38-/HLA-DR+-0.043\%-0.068\% and CD34+/CD38+/HLA-DR-0.24\%-0.51\%. Eight samples of the eighty were positive for embryonic markers. The most frequent phenotype in HUCB was CD34+ CD38+ HLA DR+. 
Conclusion. This is the first time that SSEA-4 and CD13 antigens have been reported in human umbilical cord blood cells.

Keywords: Hematopoietic stem cells, flow cytometry, umbilical cord, stem cell transplantation

Las células madre hematopoyéticas se caracterizan por su capacidad de proliferación y diferenciación en progenitores hematopoyéticos comprometidos. De acuerdo con el modelo de la hematopoyesis, el proceso de maduración de las células sanguíneas en médula ósea comienza con un reducido grupo celular denominado "células madre hematopoyéticas de largo plazo" (long-term hematopoietic stem cells, LT-HSC). Las LT-HSC son necesarias para el mantenimiento del sistema hematopoyético durante toda la vida de un organismo, y dan origen a otro grupo celular denominado "células madre hematopoyéticas de corto plazo" (short-term hematopoietic stem cells, ST-HSC), las cuales se caracterizan por su mayor cantidad, por entrar más fácilmente al ciclo celular y dar origen a los progenitores comprometidos en la hematopoyesis (1).

La mayoría de las células madre hematopoyéticas expresan el antígeno CD34, una glicoproteína de membrana que se expresa en la superficie de las células progenitoras hematopoyéticas, así como algunas células endoteliales y del estroma medular. Estudios recientes sobre la composición bioquímica y estructural de la molécula CD34, incluido el de la secuencia de los aminoácidos y carbohidratos que la componen, han revelado que este antígeno es una molécula altamente glicosilada y acídica (punto isoeléctrico $<4,0$ ), y su peso corresponde a 110.000 daltons. Otros experimentos indican que CD34 es una fosfoproteína, puesto que los procesos relacionados con fosforilación están involucrados como un mecanismo que regula el funcionamiento de las glicoproteínas de superficie y de los

\section{Correspondencia:}

Viviana Marcela Rodríguez, Carrera $7^{\text {a }}$ No 43-82, Laboratorio 105 Hematología, Edificio Félix Restrepo, Facultad de Ciencias, Pontificia Universidad Javeriana, Bogota, D.C., Colombia.

Teléfono: 3208320, ext. 4025 o 4022; fax: 3208320, ext. 4021

vivianar@javeriana.edu.co

Recibido: 24/05/05; aceptado: 23/10/05 receptores de los factores de crecimiento, lo cual podría dar una clave del papel del CD34 como un regulador de los procesos hematopoyéticos (2-5).

Otro de los marcadores que se expresa en los progenitores hematopoyéticos comprometidos es la molécula CD38, una glicoproteína expresada por muchos tipos celulares y que desempeña un papel importante en los procesos de activación y proliferación en los linfocitos maduros, además de estar involucrada en los procesos de interacción entre las células $(6,7)$.

Algunos investigadores han documentado que las células madre hematopoyéticas de ratones fetales y adultos expresan el antígeno CD38; sin embargo, no hay suficiente información acerca de la expresión de este antígeno en ratones recién nacidos y jóvenes. En un estudio se encontró que en la médula ósea de ratones recién nacidos hasta de 5 semanas no se expresaba CD38, lo que indica que la población de células madre hematopoyéticas CD38+ aparece después de la quinta semana del nacimiento y que su expresión se mantiene durante las siguientes etapas del desarrollo (8).

Además de la expresión de CD34 y CD38, se ha encontrado que la expresión del antígeno HLADR, una de las glicoproteínas de membrana asociadas al complejo mayor de histocompatibilidad de clase II, se relaciona con la diferenciación de las células hematopoyéticas. Aunque estudios recientes han documentado que existen diferencias en la expresión del HLA-DR entre células progenitoras hematopoyéticas fetales y adultas, los investigadores sugieren que el antígeno HLA-DR se asocia con el potencial de proliferación de los progenitores hematopoyéticos. Cao y colaboradores han demostrado que la expresión de los antígenos CD34 y HLA-DR se pierde gradualmente en respuesta a la interleucina-3 (IL-3), y que la pérdida de expresión del HLA-DR se asocia con la pérdida de la capacidad proliferativa de las células progenitoras hematopoyéticas (9). 
La expresión de estos tres antígenos asociados con estadios específicos de diferenciación y linajes hematopoyéticos se ha utilizado para caracterizar las células madre hematopoyéticas en médula ósea de adultos en sangre periférica, pero no en sangre de cordón umbilical (10).

La frecuencia de las células madre hematopoyéticas CD34+ en médula ósea se ha estimado entre $1 \%$ y $3 \%$ de las células mononucleares, en tanto que en sangre de cordón umbilical esta población oscila entre $0,2 \%$ y $1 \%$ (5). La expresión del antígeno CD38 en las células madre hematopoyéticas de médula ósea y sangre de cordón umbilical aumenta con la diferenciación. El inmunofenotipo CD34+ CD38- define una población altamente primitiva tanto en médula ósea como en sangre de cordón umbilical; sin embargo, existen diferencias funcionales entre estas dos poblaciones. Las células CD34+ CD38derivadas de sangre de cordón umbilical tienen una mayor capacidad clonogénica, proliferan más rápidamente en respuesta a la estimulación con citocinas y generan, aproximadamente, siete veces más progenitores que la misma población presente en médula ósea bajo condiciones in vitro. Se ha encontrado que el inmunofenotipo comúnmente caracterizado para identificar las células madre hematopoyéticas en médula ósea de adultos no aplica para las células madre hematopoyéticas de sangre de cordón umbilical. Las células CD34+ de médula ósea con expresión baja o ausente del antígeno HLA-DR son las más primitivas y las que más proliferan en cultivo. Sin embargo, en la sangre de cordón umbilical, las células CD34+ HLA-DR+ representan la población más primitiva $(11,12)$.

Los estudios han demostrado que los progenitores más primitivos de la médula ósea que expresan el antígeno CD34 no expresan los antígenos HLADR y CD38; la mayoría de las células CD34+ CD38- son HLA-DR+ y las CD34+ HLA-DR- son CD38+. Aunque ambas subpoblaciones son ricas en progenitores hematopoyéticos, se han encontrado diferencias funcionales entre ellas, ya que las células CD34+ CD38- HLA-DR+ derivadas de la médula ósea son células madre hematopoyéticas que pueden dar origen a todos los linajes hematopoyéticos in vitro, mientras que las células CD34+CD38+ HLA-DR- no lo pueden hacer $(10,11,13,14)$.

La necesidad de buscar fuentes para obtener células madre hematopoyéticas diferentes a la médula ósea ha llevado al desarrollo de investigaciones en sangre periférica y sangre de cordón umbilical. Broxmeyer y colaboradores demostraron en la década de los 80 la presencia de células madre hematopoyéticas en la sangre del cordón umbilical con capacidad de regeneración de la hematopoyesis en pacientes con enfermedades hematológicas (15).

Los estudios realizados por Piacibello demuestran que la sangre de cordón umbilical de recién nacidos a término y pretérmino contiene un número significativo de células progenitoras con un mayor potencial de formar colonias in vitro que la sangre periférica de adultos; el potencial de diferenciación y proliferación de las unidades formadoras de colonia de granulocitos, eritroides, monocitos y megacariocitos (Colony Forming Unit-Granulocyte, Erythroid, Monocyte, Megakaryocyte, UFCGEMM) también es mayor en la sangre de cordón umbilical de recién nacidos que en la sangre periférica de adultos. La frecuencia de progenitores clonogénicos en sangre de cordón umbilical es del $0,1 \%$ al $0,5 \%$ de las células mononucleares, mientras que en la sangre periférica de adultos es del $0,001 \%$ al $0,025 \%$ de las células mononucleares (16).

Las células CD34+ derivadas de sangre de cordón umbilical son capaces de generar gran cantidad de células maduras en cultivo sin reducir el número de células CD34+ en el mismo, mientras que las células CD34+ de médula ósea adulta disminuyen en el cultivo a medida que producen células maduras, lo que indica que las células primitivas que provienen de la médula ósea pierden su capacidad de autorrenovación in vitro (17)

Aunque la utilización de progenitores derivados de sangre de cordón umbilical es cada vez más popular en terapias de reemplazo medular, aún se desconoce gran parte de la distribución fenotípica de las subpoblaciones de progenitores celulares tempranos en este tipo de tejido. La identificación de las subpoblaciones de acuerdo con su fenotipo puede contribuir a determinar el 
tipo de linaje al cual corresponde una u otra población, lo que facilitaría su manipulación para inducir procesos de diferenciación celular y obtener cultivos ricos en progenitores multipotenciales que puedan facilitar terapias de reemplazo medular específicas para determinadas patologías. Las características fenotípicas relacionadas con estados de madurez y tendencia de linaje se han identificado en médula ósea, pero no en sangre de cordón umbilical. Por medio de este trabajo se determinó la distribución de las subpoblaciones de células madre más primitivas con base en la expresión de los antígenos CD34, CD38, HLA-DR, CD13 y SSEA-4, lo que permite iniciar la clasificación de subpoblaciones de progenitores de sangre de cordón umbilical para futuros estudios de proliferación y diferenciación celular.

\section{Materiales y métodos}

La población seleccionada incluyó 80 mujeres entre 18 y 37 años de edad en estado de gravidez normal a término (38 a 40 semanas de gestación) que asistían al servicio de ginecobstetricia del Hospital Universitario San Ignacio, y que cumplían con los criterios de inclusión de edad y participación voluntaria con aceptación y firma del consentimiento informado para la donación voluntaria de sangre de cordón umbilical. Otros datos como antecedentes de embarazos ectópicos, abortos o embarazos de alto riesgo, diabetes gestacional, marcadores positivos para agentes infecciosos relacionados con TORCH (toxoplasma, rubéola, citomegalovirus, herpes), sífilis y otras enfermedades infecciosas (HIV, hepatitis $B$, hepatitis $C$ ), y antecedentes de enfermedades congénitas en embarazos previos se obtuvieron de las correspondientes historias clínicas. El promedio de edad del grupo de estudio fue de 27,5 años; solamente una donante presentó eclampsia y otra paciente tenía como antecedente un embarazo ectópico; durante la recolección de las muestras solamente dos donantes de las 80 requeridas presentaron diabetes gestacional.

Se recogieron 80 muestras de sangre de cordón umbilical en la población de estudio, que fueron procesadas en el Laboratorio de Hematología de la Facultad de Ciencias de la Pontificia
Universidad Javeriana. La variable que se tuvo en cuenta en este estudio fue la expresión de los antígenos de superficie CD34, CD38 y HLA-DR para las células madre hematopoyéticas y de los antígenos CD34, CD13 y SSEA-4 como antígenos relacionados con células madre embrionarias a partir de la población de células que tenía baja complejidad y tamaño según el programa CellQuest ${ }^{\circledR}$ de Becton Dickson ${ }^{\circledR}$. Para recolectar las muestras de sangre de cordón umbilical después del parto, y antes de la expulsión de la placenta, se pinzaba el cordón umbilical a $5 \mathrm{~cm}$ del ombligo del recién nacido con dos pinzas para luego cortar el cordón entre ellas. La pinza que quedaba en el cordón umbilical unido a la placenta se abría, dejando que la sangre fluyera espontáneamente para recolectar en tubo con anticoagulante EDTA hasta obtener $5 \mathrm{~mL}$. Estas muestras se transportaron a temperatura ambiente y en oscuridad hasta el Laboratorio de Hematología para su procesamiento.

Para cada muestra de sangre de cordón umbilical se realizaron tres marcaciones: control de isotipo, células hematopoyéticas y antígenos embrionarios. El procedimiento se realizó marcando $70 \mu \mathrm{l}$ de sangre de cordón umbilical con el correspondiente coctel de anticuerpos así: para el control de isotipo se utilizaron $5 \mu \mathrm{l}$ de Mouse $\operatorname{lgG}_{1}$ FITC, Mouse $\lg G_{1}$ Cy-Chrome ${ }^{5}$, mouse lgG ${ }_{2 a}$ PE y Mouse lgG APC; $_{1}$ para la determinación de antígenos hematopoyéticos se marcó con $10 \mu \mathrm{l}$ de anticuerpo antiCD34 FITC (clon 581 PharMingen $®), 5 \mu$ de antiCD38 Cy-Chrome ${ }^{5}$ (clon HIT2 PharMingen $®$ ) y 5 $\mu$ de anti-HLA-DR PE (clon G46-6 PharMingen $®$ ); y para la identificación de antígenos embrionarios se utilizaron $10 \mu \mathrm{l}$ de anti-SSEA-4 (clon MC-81370 R\&D System $\left.{ }^{\circledR}\right), 20 \mu$ le Rat-AntiMouse IgG1 PE y $5 \mu$ ldel anticuerpo anti-CD13 APC (clon MC813-70 R\&D System $\left.{ }^{\circledR}\right)$.

Realizada la marcación, los tubos se llevaron a incubación durante 30 minutos a $4^{\circ} \mathrm{C}$ en oscuridad, y finalizado este tiempo se realizó un lavado con solución tampón salino fosfato (PBS) durante 5 minutos a 1.800 rpm; luego, se adicionaron 500 $\mu \mathrm{l}$ de solución tampón de lisis $1 \mathrm{X}$ (Buffer lysis $10 X ® B D($ ) en cada uno de los tubos y éstos se llevaron a incubación durante 15 minutos a temperatura ambiente en oscuridad. Luego de la 
lisis, se realizaron dos lavados de las células con solución tampónde citometría (PBS azida de sodio al $0,1 \% \mathrm{pH} 7,2-7,4)$ durante 5 minutos a 1.800 rpm y se procedió a fijar las células con $500 \mu \mathrm{l}$ de buffer de fijación (PBS paraformaldehído 0,5\% pH: $7,2-7,4)$. Por último, se realizó la lectura de las muestras en el citómetro de flujo FACS Calibur Becton Dickinson $® ;$; se adquirieron 50.000 eventos de la región que corresponde a una población celular de baja complejidad (side scatter) y tamaño (forward scatter). Con el programa Cell Quest ${ }^{\circledR}$ se realizó el análisis de los datos seleccionando inicialmente la población positiva para el antígeno CD34; a partir de ésta, se observó la expresión de los antígenos CD38 y HLADR en cada una de las muestras. Para el análisis de la expresión de los antígenos embrionarios se utilizó la misma población en cuanto a tamaño y complejidad interna, pero el análisis de la expresión de SSEA-4 y CD13 se determinó a partir de la población en ausencia del antígeno CD34. La definición de los cuadrantes se realizó a partir de controles de isotipo $(11,13)$.

\section{Consideraciones éticas}

El estudio se realizó teniendo en cuenta la normatividad ética enunciada en la Resolución 008430, capítulo IV, expedida por el Ministerio de Salud en 1993, que regula "La investigación en mujeres en edad fértil, embarazadas, durante el trabajo de parto, puerperio, lactancia y recién nacidos; de la utilización de embriones, óbitos y fetos y de la fertilización artificial". La participación de los pacientes en este estudio fue voluntaria y sin ánimo de lucro. Los participantes recibían un consentimiento que explicaba de forma clara y precisa el objetivo de la toma de muestra de sangre de cordón umbilical. Este consentimiento informado fue aprobado por el Comité de Investigación y Ética de la Facultad de Ciencias de la Universidad Javeriana, así como por el Comité Científico del Hospital Universitario San Ignacio con el apoyo del Instituto de Genética Humana de la Universidad Javeriana.

\section{Estadística}

Para el cálculo del tamaño de la muestra se utilizó una fórmula para la estimación puntual de la media con un error tipo I de 0,05 y un error tipo II de
0,20. La desviación estándar de la población conocida fue de seis (5). Para realizar la prueba de hipótesis se debía probar la normalidad de los datos con la prueba de Shapiro Wilk; según esta prueba, los datos no se distribuyeron normalmente $(p<0,05)$, por esto fue necesario aplicar una prueba de hipótesis no paramétrica, para lo cual se recurrió a la prueba de la mediana o prueba del signo en el programa Statistix 6.0.

\section{Resultados}

El valor mínimo de la proporción de las subpoblaciones de células madre hematopoyéticas en sangre de cordón umbilical fue de $0,03 \%$ y el valor máximo de $1,82 \%$, con una mediana de $0,28 \%(\mathrm{Pt} 25 ; 75)$. A partir de los datos obtenidos, se puede afirmar que existe evidencia estadísticamente significativa para decir que la mediana de la proporción de las subpoblaciones de células madre hematopoyéticas en las muestras analizadas es mayor a $0,2 \%(p=0,0010)$. En la figura 1 se presenta el análisis con el programa Cell Quest ${ }^{\circledR}$ de los antígenos relacionados con células madre hematopoyéticas en una de las muestras del estudio. La figura 2 representa la distribución de los inmunofenotipos en la población celular seleccionada a partir de las 80 muestras obtenidas. Para cada una de las subpoblaciones de células madre hematopoyéticas se calcularon los intervalos de confianza (IC : 95\%), obteniéndose los siguientes rangos: CD34+ CD38- HLA-DR- = 0,0153\% a 0,0234\%; CD34+ CD38+ HLA-DR- $=0,0191 \%$ a $0,0296 \%$; CD34+ CD38- HLA-DR+ $=0,0427 \%$ a $0,0676 \%$; CD34+ CD38+ HLA-DR+ = 0,2427\% a 0,5117\%.

Aunque nuestro estudio muestra que el inmunofenotipo más frecuente en sangre de cordón umbilical fue CD34+ CD38+ HLA-DR+, es importante destacar que, a pesar de que el rango fue menor, también se encontró una población CD34+ CD38- HLA-DR-.

En cuanto a la expresión de antígenos embrionarios, la figura 3 presenta el análisis de una muestra positiva y una negativa para la expresión de estos antígenos. La expresión de los antígenos CD13 y SSEA-4 en las 80 muestras de sangre de cordón umbilical analizadas se detectó en ocho muestras de acuerdo con el con- 

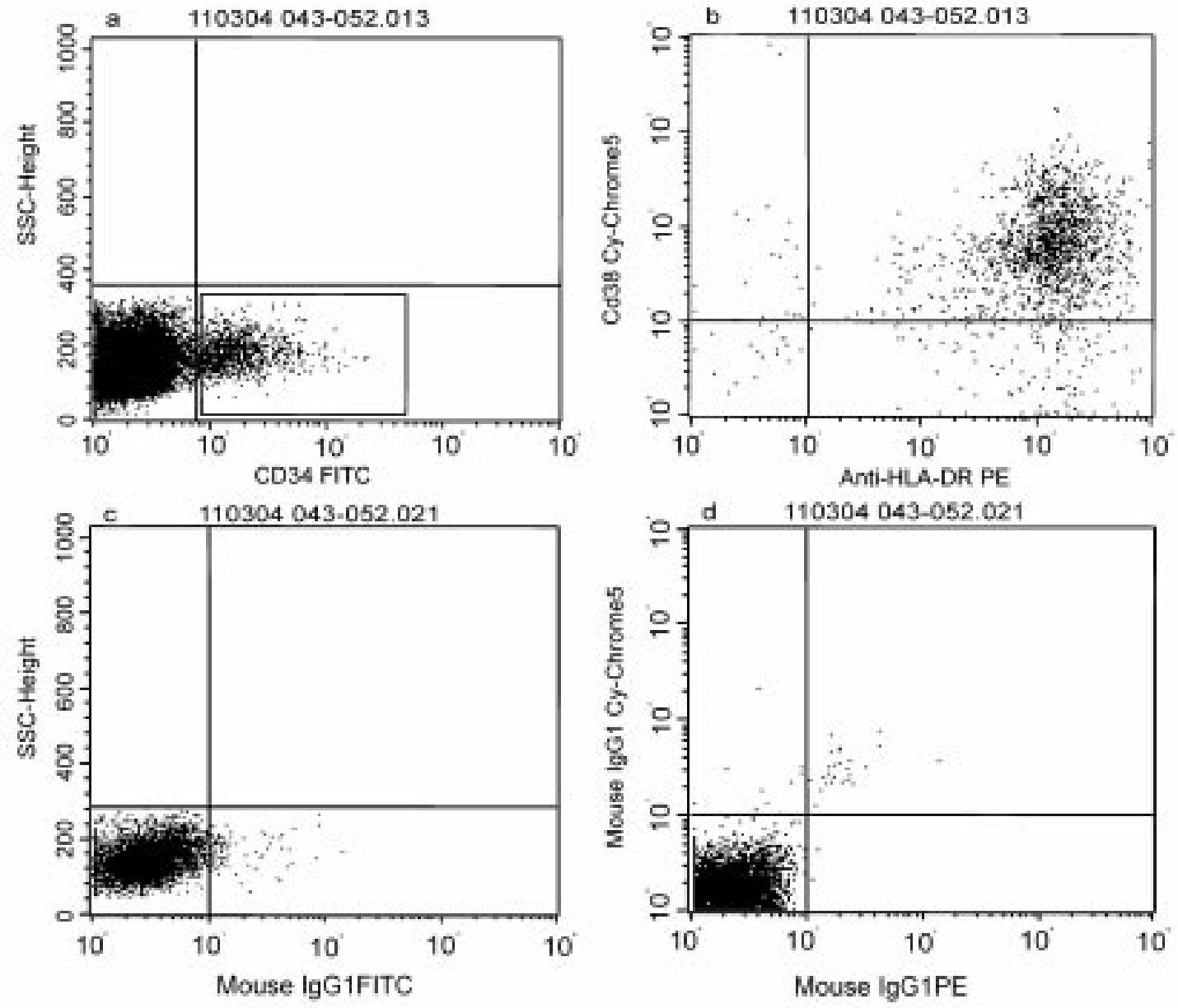

Figura 1. Representación del análisis de la expresión de inmunofenotipos relacionados con células madre hematopoyéticas. A partir de la población de células seleccionada (baja complejidad y tamaño) se determinaron aquéllas que expresaban el antígeno CD34+ (a); luego, en esta población se analizó la expresión de los antígenos CD38 y HLA-DR (b). La determinación de los controles de isotipo permitió establecer los correspondientes cuadrantes para el análisis estadístico (controles de isotipo en figuras c y d). Los datos fueron analizados con el programa CellQuest ${ }^{\circledR}$ de Becton Dickson ${ }^{\circledR}$.

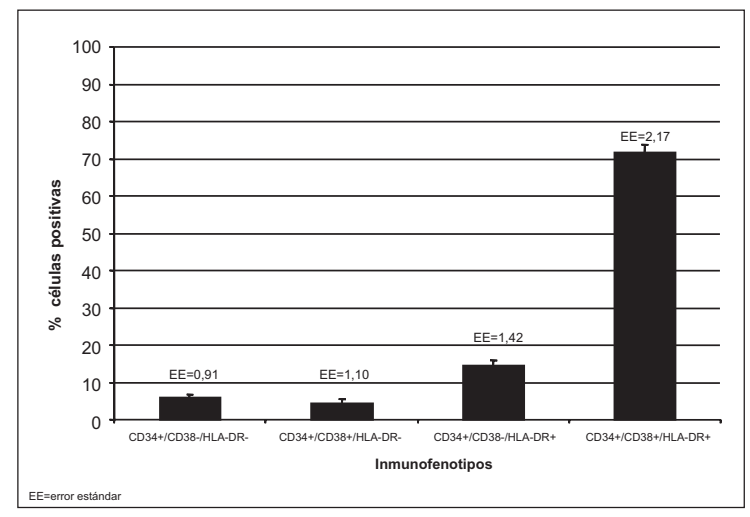

Figura 2. Expresión de los inmunofenotipos relacionados con células madre hematopoyéticas. Se presentan los porcentajes de células que expresan los correspondientes inmunofenotipos en la población de estudio (\% células positivas), la cual fue seleccionada de acuerdo con características de baja complejidad (side scatter) y tamaño (forward scatter). 
trol de isotipo utilizado; por medio de un análisis igual al de los antígenos hematopoyéticos, la expresión de los antígenos embrionarios se determinó con la ayuda del programa Cell Quest $\AA$. La figura 4 presenta la expresión de los antigenos SSEA-4 y CD13 en las ocho muestras positivas.

\section{Discusión}

La presencia de células madre hematopoyéticas en sangre de cordón umbilical se demostró en 1974. Sin embargo, fue diez años más tarde que se documentó la presencia de progenitores hematopoyéticos en sangre de cordón umbilical; desde entonces, se ha incrementado el interés por el uso de la sangre de cordón umbilical como recurso alterno para obtener células madre hematopoyéticas diferentes a las de médula ósea (5). Se ha encontrado que la molécula CD34 se expresa en la mayoría de las células madre hematopoyéticas, por lo que se ha convertido en el principal marcador para su caracterización. La frecuencia de este antígeno en sangre de cordón umbilical se ha estimada entre el $0,2 \%$ y el $1 \%$ del total de las células de la sangre de cordón umbilical (13), lo que concuerda con los resultados obtenidos en este estudio, en el cual la proporción fue mayor al $0,2 \%(p=0,0010)$.

Muchos estudios han demostrado que las células CD34+ de médula ósea y de sangre de cordón
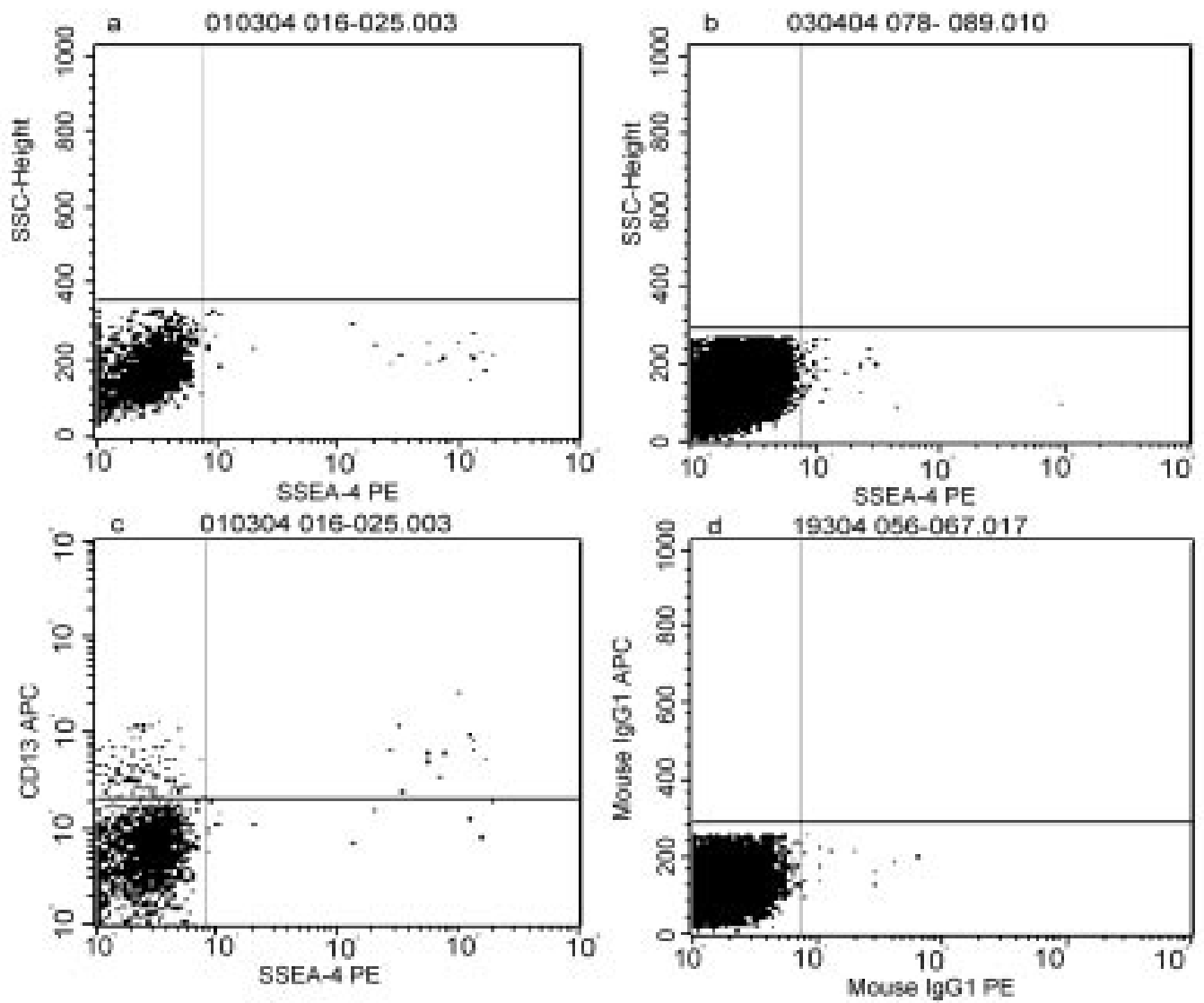

Figura 3. Kepresentacion del analısıs de la expresıon de antigenos embrionarıos. A partır de la poblacıon de celulas seleccionada (baja complejidad y tamaño) se determinaron aquéllas que expresaban el antígeno SSEA-4 en ausencia del CD34 (a); la figura b representa una muestra que no presentó expresión de SSEA-4. Posteriormente, se observó en la población positiva para SSEA-4 la coexpresión con CD13 (c). La determinación de los controles de isotipo permitió establecer los correspondientes cuadrantes para el análisis estadístico (d). Los datos se analizaron con el programa CellQuest ${ }^{\circledR}$ de Becton Dickson ${ }^{\circledR}$ 


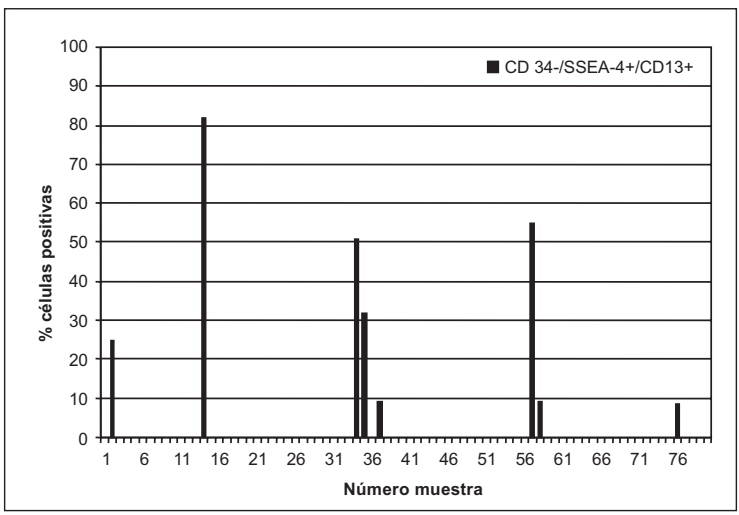

Figura 4. Expresión de los inmunofenotipos relacionados con antígenos embrionarios. Se presentan los porcentajes de células que expresan los antígenos SSEA-4 y CD13 en ausencia de CD34 en la población de estudio (\% células positivas), la cual fue seleccionada de acuerdo con características de baja complejidad (side scatter) y tamaño (forward scatter).

umbilical son heterogéneas y contienen una gran variedad de células madre que se encuentran en diferentes estadios; sin embargo, éste es el primer estudio de inmunofenotipificacion de poblaciones de células madre hematopoyéticas realizado con sangre de cordón umbilical en una población colombiana. Ello constituye un aporte para la optimización de la separación de progenitores hematopoyéticos a partir de sangre de cordón umbilical con base en los rangos encontrados en nuestro estudio. Hao y colaboradores encontraron que la subpoblación de células madre hematopoyéticas CD34+CD38- es muy primitiva teniendo como base el estado del ciclo celular en el que se encuentran las células y en su capacidad de proliferación in vitro (11). Traycoff reportó que la población CD34+ HLA-DR+ en sangre de cordón umbilical es más primitiva que la población CD34+ HLA-DR-, en contraste con los hallazgos en médula ósea adulta en donde las células más primitivas son las células CD34+ HLA-DR- (12). Existe controversia acerca de la coexpresión de los antígenos CD34 y HLA-DR, ya que, aunque la población de células madre hematopoyéticas más primitiva en sangre de cordón umbilical es la que co-expresa CD34 y HLA-DR, se ha encontrado una población de células con el fenotipo CD34+ HLA-DR- (18). A pesar de que se han realizado varios estudios acerca del inmunofenotipo de las células madre hematopoyéticas con base en la expresión de los antígenos CD34/CD38 y CD34/ HLA-DR, hasta el momento se desconocían los fenotipos de las células madre hematopoyéticas de sangre de cordón umbilical que relacionaran los tres antígenos. Por ser éste el primer estudio acerca de las subpoblaciones de células madre hematopoyéticas en sangre de cordón umbilical con base en la expresión de los antígenos CD34, CD38 y HLA-DR, se encontraron cuatro subpoblaciones de células madre hemato-poyéticas similares a las que se reportan en la médula ósea y que corresponden a los fenotipos CD34+/CD38/HLA-DR-, CD34+/CD38-/HLA-DR+, CD34+/ CD38+/HLA-DR- y CD34+/CD38+/HLA-DR+. El rango de cada una de estas subpoblaciones es diferente, encontrándose que las células con el fenotipo CD34+ CD38+ HLA-DR+ se encuentran en mayor proporción con relación a las otras tres subpoblaciones. No se determinaron los recuentos relativos (\%) y absolutos (células $/ \mathrm{mL}$ ) de cada una de las subpoblaciones encontradas, ya que la distribución de los datos no fue normal; por este motivo se optó por determinar los intervalos de confianza.

En cuanto a los estudios sobre células madre embrionarias, sólo se pueden realizar a partir de las células provenientes de la etapa de blastocisto, lo que implica la manipulación de embriones. Las connotaciones éticas de tal posibilidad son innegables, razón por la cual los investigadores están tratando de encontrar otras fuentes con características similares a las de estas células, como lo son las de médula ósea. Recientemente se documentó la presencia de una población de células madre en médula ósea con un comportamiento similar al de las células madre embrionarias, las cuales expresan altos niveles de los antígenos CD13 y SSEA-4, y que fueron denominadas "progenitores celulares adultos multipotentes" (19).

Hasta el momento no existían reportes acerca de células que expresaran antígenos embrionarios en sangre de cordón umbilical, lo que motivó la búsqueda de células madre con características embrionarias, así como la identificación de cada una de las subpoblaciones de células madre hematopoyéticas derivadas de sangre de cordón 
umbilical. En este estudio se encontró la coexpresión de los antígenos CD13 y SSEA-4 en ocho de las 80 muestras analizadas, lo cual indica que en sangre de cordón umbilical posiblemente existan progenitores celulares con características similares a las encontradas en células embrionarias; sin embargo, es necesario explorar la expresión de otros antígenos embrionarios como SSEA-3, TRA-1-60, TRA-1-81, factores de transcripción como el Oct-4, y marcadores intracelulares como la fosfatasa alcalina, ya que estas proteínas tienen una cinética de expresión similar a SSEA-4. Tamagawa y colaboradores lograron el establecimiento de una línea de células madre con características similares a las de los progenitores embrionarios a partir de membranas amnióticas humanas; esta línea celular mantiene un cariotipo normal y altos niveles de fosfatasa alcalina (20); de forma similar, Baal y colaboradores detectaron en sangre de cordón umbilical poblaciones celulares que coexpresan CD34 y CD133, las cuales, después de cuarenta días de cultivo, expresaron marcadores de fenotipo pluripotente como Sox-1, Sox-2, Rex-1 y Oct-4 (21); estos hallazgos, y los encontrados en nuestro estudio, respaldan la posibilidad de la existencia de progenitores pluripotentes en sangre de cordón umbilical con alta capacidad de proliferación y diferenciación hacia diversos tejidos.

La caracterización fenotípica de las subpoblaciones de células madre hemato-poyéticas, y el posible hallazgo de células con expresión de antígenos embrionarios en sangre de cordón umbilical, permitirá establecer protocolos para el aislamiento, purificación y cultivo de estas poblaciones celulares con base en su inmunofenotipo, lo que en un futuro cercano permitiría profundizar en los estudios relacionados con la diferenciación de precursores hematopoyéticos derivados de esta fuente $y$, probablemente, caracterizar y explorar poblaciones celulares que expresan antígenos relacionados con las primeras etapas del desarrollo embrionario.

\section{Agradecimientos}

Este trabajo fue realizado gracias a la colaboración del Servicio de Ginecobstetricia del Hospital Universitario San Ignacio y la de todo el personal que trabaja en esta área. Igualmente, agradecemos a Ignacio Zarante, profesor del Instituto de Genética Humana en la Facultad de Medicina, y al personal de la Unidad de Citometría de Flujo del Departamento de Microbiología en la Facultad de Ciencias de la Pontificia Universidad Javeriana.

\section{Conflicto de intereses}

Esta investigación es de carácter exclusivamente académico, por lo tanto, no presenta conflicto de intereses con la empresa pública o con la empresa privada.

\section{Financiación}

El apoyo financiero fue garantizado por la Vicerrectoría Académica de la Pontificia Universidad Javeriana.

\section{Referencias}

1. Ivanova NB, Dimos JT, Schaniel C, Hackney JA, Moore KA, Lemichka IR. A stem cell molecular signature. Science 2002;298:601-4.

2. Fackler MJ, Civin $\mathrm{Cl}$, Sutherland DR, Baker MA, May WS. Activated protein kinase $C$ directly phosphorylates the CD34 antigen on hematopoietic cells. J Bio Chem 1990;265:11056-61.

3. Burn T, Satterthwaite AB, Tenen DG. The human CD34 hematopoietic stem cell antigen promoter and a $3^{\prime}$ enhancer direct hematopoietic expression in tissue culture. Blood 1992;80:3051-9.

4. Healy L, May G, Gale K, Grosveld F, Greaves M, Enver T. The stem cell antigen CD34 functions as a regulator of hematopoietic cell adhesion. Proc Natl Acad Sci USA 1995;92:12240-4.

5. Mayani H, Lansdorp PM. Biology of umbilical cord blood derived hematopoietic stem/progenitor cells. Stem Cells 1998;16:153-65.

6. Funaro A, Reinis M, Trubiani O, Santi S, Di Primio R, Malavasi F. CD38 functions are regulated through an internalization step. J Immunol 1998;160:2238-47.

7. Funaro A, Spagnoli GC, Ausiello CM, Alessio M, Roggero S, Delia D et al. Involvement of the multilineage CD38 molecule in a unique pathway of cell ativation and poliferation. J Immunol 1990;145:2390-6.

8. Higuchi $\mathbf{Y}$, Zeng Y, Ogawa M. CD38 expression by hematopoietic stem cells of newborn and juvenile mice. Leukemia 2003;17:171-4.

9. Cao LX, Le Brouse-Kerdiles MC, Clay D, Oshevski S, Jasmin C, Krief P. Implication of a new molecule IK in CD34+ hematopoietic progenitor cell proliferation and differentiation. Blood 1997;89:3615-23. 
10. Opie TM, Shields LE, Andrews RG. Cell-surface antigen expression in early and term gestation fetal hematopoietic progenitor cells. Stem Cells 1998;16:343-8.

11. Hao QL, Shah AJ, Thiemann FT, Smogorzewska EM, Crooks GM. A functional comparison of CD34+CD38- cells in cord blood and bone marrow. Blood 1995;86:3745-53.

12. Traycoff CM, Abboud MR, Laver J, Brandt JE, Hoffman R, Law P et al. Evaluation of the in vitro behaviour of phenotypically defined populations of umbilical cord blood hematopoietic progenitor cells. Exp Hematol 1994;22:215-22.

13. D‘Arena G, Musto P, Cascavilla N, Di Giorgio G, Zendoll F, Carotenuto M. Human umbilical cord blood: immunophenotypic heterogeneity of CD34+ hematopoietic progenitor cells. Haematologica 1996;81:404-9.

14. Sakabe $\mathbf{H}$, Ohmizono $\mathbf{Y}$, Tanimukai $\mathbf{S}$, Kimura $\mathbf{T}$, Mori KJ, Abe T et al. Functional differences between subpopulations of mobilized peripheral blood-derived CD34+ cells expressing different levels of HLA-DR, CD33, CD38 and c-kit antigens. Stem Cells 1997;15:7381.

15. Rubinstein P, Stevens CE. Placental blood for bone marrow replacement: the New York Blood Center's program and clinical results. Baillieres Best Pract Res Clin Haematol 2000;13:565-84.
16. Piacibello W, Sanavio F, Garetto L, Severino A, Bergandi D, Ferrario $\mathbf{J}$ et al. Extensive amplification and self-renewal of human primitive hematopoietic stem cells from cord blood. Blood 1997;89:2644-53.

17. Emerson SG. Ex vivo expansion of hematopoietic precursors, progenitors, and stem cells: the next generation of cellular therapeutics. Blood 1996;87:3082-8.

18. Thomas SJ, Camping CP, Ziegler BL. Phenotype analysis of hematopoietic CD34+ cell populations derived from human umbilical cord blood using flow cytometry and cDNA- polymerase chain reaction. Blood 1994;83:2103-14.

19. Jiang Y, Vaessen B, Lenvik T, Blackstad M, Reyes $\mathbf{M}$, Verfaillie $\mathbf{C M}$. Multipotent progenitor cells can be isolated from postnatal murine bone marrow, muscle and brain. Exp Hematol 2002;30:896-904.

20. Tamagawa T, Ishiwata I, Saito S. Establishment and characterization of a pluripotent stem cell line derived from human amniotic membranes and initiation of germ layers in vitro. Hum Cell 2004;17:125-30.

21. Baal N, Reisinger K, Jahr H, Bohle RM, Liang $\mathbf{O}$, Munstedt K et al. Expression of transcription factor Oct-4 and other embryonic genes in CD133 positive cells from human umbilical cord blood. Thromb Haemost 2004;92:767-75. 